\title{
Pesticide-Originated Persistent Organic Pollutants in Agricultural Waterways in Chungcheong Province, Korea
}

\author{
Hwa-Sung Lee $\cdot$ Hwang-Ju Jeon · Hoi-Seon Lee* · Sung-Eun Lee* \\ 충청지역 농업용수 중 농약 유래 POPs의 모니터링 연구 \\ 이화성 · 전황주 · 이회선* · 이성은*
}

Received: 4 August 2015 / Accepted: 13 August 2015 / Published Online: 31 December 2015

(C) The Korean Society for Applied Biological Chemistry 2015

\begin{abstract}
Persistent organic pollutants (POPs) including banned organochlorine pesticides, are found in Korean agricultural environments. Their translocation from agricultural environment to major crops has been reported. In this study, the POPs in 15 different agricultural waters of the Chungchung Province were monitored and all samples were prepared, followed by liquidliquid fractionation and column chromatography prior to analysis using gas chromatography. Among pesticide-originated persistent organic pollutants, $\alpha$-endosulfan was determined in the range of 0.01 to $1.13 \mathrm{ng} / \mathrm{mL}$. $\beta$-Endosulfan was determined in the range of 0.01 to $0.55 \mathrm{ng} / \mathrm{mL}$, and endosulfan sulfate was ranged from 0.13 to $1.13 \mathrm{ng} / \mathrm{mL}$. The total sum of endosulfans reached the range of 0.38 to $1.18 \mathrm{ng} / \mathrm{mL}$. Three pesticides being used currently were also found in samples as $2.03-2.05 \mathrm{ng} / \mathrm{mL}$ for triadimefon, $0.26-$
\end{abstract}

H.-S. Lee and H.-J. Jeon contributed equally.

\section{H.-S. Lee}

Quality Control Department, Korea Good Herbs Distribution Center, Andong 760-801, Republic of Korea

H.-J. Jeon · S.-E. Lee

School of Applied Biosciences, Kyungpook National University, Daegu 702-701, Republic of Korea

\section{H.-S. Lee}

Department of Bioenvironmental Chemistry, College of Agriculture \& Life Science, Chonbuk National University, Jeonju 561-756, Republic of Korea

*Corresponding authors (H.-S. Lee: hoiseon@jbnu.ac.kr;

S.-E. Lee: selpest@knu.ac.kr)

This is an Open Access article distributed under the terms of the Creative Commons Attribution Non-Commercial License (http://creativecommons. org/licenses/by-nc/3.0/) which permits unrestricted non-commercial use, distribution, and reproduction in any medium, provided the original work is properly cited.
$0.33 \mathrm{ng} / \mathrm{mL}$ for tolyfluanid, and $1.34-3.85 \mathrm{ng} / \mathrm{mL}$ for chlorpyrifos. Taken together, endosulfans were introduced in the agricultural waters and their fates need continuous monitoring.

Keywords endosulfan - endosulfan sulfate $\cdot$ monitoring · Pesticide-originated persistent organic pollutants

현대 농산업 분야에서 농약의 사용은 농산물의 안정한 생산에 있어 그 중요성이 있으나, 유기염소계 농약들은 농업환경 중 잔 류성이 길며, 생산 작물로의 이동성이 구명되어 이들의 사용 및 관리가 전세계적으로 관심의 대상이 되고 있다(Bordas 등 2011; Park, 2011; Kim 등, 2014). 1995년 스톡홀름 협약에 의거하여 국내에서 관리 대상이 된 12 종의 잔류유기오염물질(persistent organic pollutants, POPs)은 현재 23종으로 확대되었으며 이 중 14종은 농약유래 POPs로 알려져 있다(Kim 등, 2014). 이들 농 약 유래 POPs 중 chlodecone, hexachlorobenzene, mirex 및 pentachlorobenzene 등은 국내에서 사용된 바 없다. 농약 유래 POPs는 살충제 또는 살균제로서 사용하였으며 이들의 잔류성은 이들의 물질 성질과 연관되어 이해되어 왔다(Tsai, 2010). 농약 유래 POPs의 환경 호르몬으로서의 독성 외에도 다양한 인체 및 환경 독성이 알려져 있는데, 이들의 국내 환경 중 잔류량은 여 러 선행 연구를 통하여 보고되었다(Tsai, 2010). 농경지 내 aldrin, chlordane, DDT, dieldrin, endosulfan, heptachlor, $\alpha$-hexachlorocyclohexane, $\beta$-hexachlorocyclohexane 등의 잔류량은 0.001 로 부터 $0.64 \mathrm{mg} / \mathrm{kg}$ 까지 잔류하고 있으며 chlodecone, hexachlorobenzene, mirex 및 pentachlorobenzene의 잔류는 보 고된 바 없다(Kim과 Smith, 2001; Choi와 Chun, 2007; Park, 2011). 더불어 국내 모유 중 DDT의 경우 $225.1 \mathrm{mg} / \mathrm{kg}$ fat의 농도로 발견되었으며, 이외에도 heptachlor 및 $\beta$-hexachlorocyclohexane의 경우 각각 29.0 및 $49.0 \mathrm{mg} / \mathrm{kg}$ fat의 농도로 발 
Table 1 List of pesticide-originated persistent organic pollutants and currently used pesticides as categorized by their retention time when they were analyzed using GC-ECD

\begin{tabular}{|c|c|}
\hline Type and numbers & Pesticide-originated POPs and some currently used pesticides \\
\hline $\begin{array}{l}\text { Type } 1 \text { pesticides including POPs } \\
\qquad(17)\end{array}$ & $\begin{array}{l}\alpha \text {-BHC (7.037)*, } \beta \text {-BHC (7.972), } \delta \text {-BHC (8.849), } \gamma \text {-BHC (10.593), Aldrin (11.536), Triadimefon (11.660), } \\
\text { Pendimethalin (12.509), Captan (15.272), Triflumizole (16.385), p, } p^{\prime} \text {-DDE (19.645), Dieldrin (19.774), } \\
\text { Endrin (20.154), p,p'-DDD (21.047), o, } p^{\prime} \text {-DDT (22.401), p, } p^{\prime} \text {-DDT (28.167), Methoxychlor (30.566), } \\
\text { Cypermethrin (37.423) }\end{array}$ \\
\hline $\begin{array}{l}\text { Type } 2 \text { pesticides including POPs } \\
\qquad(15)\end{array}$ & $\begin{array}{l}\text { Quintozene (9.038), Chlorothalonil (9.960), Chlorpyrifos (10.882), Tolyfluanid (11.824), Procymidone (12.690), } \\
\alpha \text {-Endosulfan (15.405), Myclobutanil (16.928), Kresoxim-methyl (17.516), } \beta \text {-Endosulfan (18.437), } \\
\text { Endosulfan-sulfate (21.673), Acetamiprid (24.777), Bifenthrin (29.147), Fenpropathrin (29.575), } \\
\text { Fenarimol (32.699), Azoxystrobin (43.565) }\end{array}$ \\
\hline
\end{tabular}

*The numbers in parentheses indicates the retention time in minutes when the samples or standards were analyzed using GC-ECD with the operating condition as shown in Table 3.

Table 2 Grid references of locations of agricultural waters samples

\begin{tabular}{cccc}
\hline Sample No. & Date collected & Latitude (N) & Longitude (E) \\
\hline 1 & 22.4 .2015 & $36^{\circ} 45^{\prime} 51^{\prime \prime}$ & $126^{\circ} 53^{\prime} 3^{\prime \prime}$ \\
2 & 22.4 .2015 & $36^{\circ} 45^{\prime} 59^{\prime \prime}$ & $126^{\circ} 52^{\prime} 49^{\prime \prime}$ \\
3 & 22.4 .2015 & $36^{\circ} 45^{\prime} 48^{\prime \prime}$ & $126^{\circ} 53^{\prime} 22^{\prime \prime}$ \\
4 & 22.4 .2015 & $36^{\circ} 45^{\prime} 38^{\prime \prime}$ & $126^{\circ} 53^{\prime} 38^{\prime \prime}$ \\
5 & 22.4 .2015 & $36^{\circ} 45^{\prime} 24^{\prime \prime}$ & $126^{\circ} 53^{\prime} 48^{\prime \prime}$ \\
6 & 22.4 .2015 & $36^{\circ} 36^{\prime} 46^{\prime \prime}$ & $126^{\circ} 49^{\prime} 26^{\prime \prime}$ \\
7 & 22.4 .2015 & $36^{\circ} 37^{\prime} 14^{\prime \prime}$ & $126^{\circ} 50^{\prime} 30^{\prime \prime}$ \\
8 & 22.4 .2015 & $36^{\circ} 36^{\prime} 22^{\prime \prime}$ & $126^{\circ} 52^{\prime \prime} 2^{\prime \prime}$ \\
9 & 22.4 .2015 & $36^{\circ} 37^{\prime} 27^{\prime \prime}$ & $126^{\circ} 52^{\prime} 39^{\prime \prime}$ \\
10 & 22.4 .2015 & $36^{\circ} 37^{\prime} 33^{\prime \prime}$ & $126^{\circ} 52^{\prime} 42^{\prime \prime}$ \\
11 & 22.4 .2015 & $36^{\circ} 45^{\prime} 13^{\prime \prime}$ & $127^{\circ} 17^{\prime} 58^{\prime \prime}$ \\
12 & 22.4 .2015 & $36^{\circ} 44^{\prime} 51^{\prime \prime}$ & $127^{\circ} 17^{\prime} 53^{\prime \prime}$ \\
13 & 22.4 .2015 & $36^{\circ} 43^{\prime} 47^{\prime \prime}$ & $127^{\circ} 17^{\prime} 56^{\prime \prime}$ \\
14 & 22.4 .2015 & $36^{\circ} 51^{\prime} 41^{\prime \prime}$ & $127^{\circ} 26^{\prime} 26^{\prime \prime}$ \\
15 & 22.4 .2015 & $36^{\circ} 52^{\prime} 13^{\prime \prime}$ & $127^{\circ} 25^{\prime} 41^{\prime \prime}$ \\
\hline
\end{tabular}

견되었다(Kim 등, 2013). 유의할 사안은 국내에서 미사용 농약 이었던 hexachlorobenzene이 모유 중 $20.6 \mathrm{mg} / \mathrm{kg}$ fat의 농도로 발견되었다(Kim 등, 2013). 이는 이 농약이 사용허가 되었던 국 가로부터 수입된 농산물 및 농산가공품을 섭취한 결과로써 예 측할 수가 있겠다.

따라서, 이러한 농약유래 POPs의 국내 농업환경 중 잔류하 는 농도가 미칠 수 있는 인체 및 환경 영향 평가를 위하여 국 내 농업환경 중 잔류하는 농약유래 $\mathrm{POPs}$ 의 잔류 양상을 조사 하였으며, 농경지 토양을 위주로 실시하였다.

시약 및 표준품. Hexane, acetone, dichloromethane, acetonitrile, sodium sulfate anhydrous 등 본 실험에서 사용된 용매는 잔류 농약분석용이었으며, 정제용 실리카겔은 Zeochem AG (Uetikon, Germany)사의 $60-200 \mathrm{~mm}$ 크기의 것을 $130^{\circ} \mathrm{C}$ 에서 24 시간 활 성화시킨 후 사용하였다. 농약 표준품은 Chemservice Inc. (USA)에서 구입한 순도 $95 \%$ 이상의 것을 사용하였으며 이들 의 분석 시 머무름 시간을 확인하여 표쥰용액 농도 및 표준용 액 혼합조합을 만들어 사용하였다. 이들의 혼합조합은 type 1 과 2로 나뉘었으며 각각의 조합에 속한 농약은 Table 1에 나타내 었다(Fig. 1).

농업용수 시료 전처리 및 검출한계. 충정도 지역의 농업용수 중 15 곳을 선별하여 시료 중 POPs의 잔류를 분석하는데 이용하였 으며, 이들의 각 방위는 Table 2에 자세히 나타내었다. 시료전
Table 3 Operating conditions of gas chromatography instruments for analyzing residual pesticides

\begin{tabular}{ccc}
\hline \multirow{2}{*}{ Content } & GC/MSD & GC-ECD \\
& Agilent 7890A GC/ & Agilent 7890A GC \\
\hline \multirow{3}{*}{ Column } & $\mathrm{HP}-5$ & $\mathrm{HP}-5$ \\
& $(30 \mathrm{~m} \times 0.25 \mathrm{~mm} \times$ & $(30 \mathrm{~m} \times 0.25 \mathrm{~mm} \times$ \\
& $0.25 \mathrm{~mm})$ & $0.25 \mathrm{~mm})$ \\
\hline \multirow{3}{*}{ Oven temp. } & $100^{\circ} \mathrm{C}(2 \mathrm{~min}) \rightarrow$ & $160(2 \mathrm{~min}) \rightarrow 5^{\circ} \mathrm{C} / \mathrm{min} \rightarrow$ \\
& $10^{\circ} \mathrm{C} / \mathrm{min} \rightarrow$ & $225^{\circ} \mathrm{C}(10 \mathrm{~min}) \rightarrow$ \\
& $280^{\circ} \mathrm{C}(15 \mathrm{~min})$ & $5^{\circ} \mathrm{C} / \mathrm{min} \rightarrow$ \\
Injector (Inlet) temp. & $260^{\circ} \mathrm{C}(\mathrm{split} 10: 1)$ & $250^{\circ} \mathrm{C}(\mathrm{split} 50: 1)$ \\
\hline Detector (Aux) temp. & Interface: $280^{\circ} \mathrm{C}$ & $\mathrm{ECD}: 300^{\circ} \mathrm{C}$ \\
\hline
\end{tabular}

처리 방법은 잔류성유기오염물질공정시험기준(ES 10903.1)을 따 랐으며, 액상시료는 dichloromethane과 액액 분배 후 회전증발 농축기(RV 10 basic, IKA, Germany)를 사용하여 완전농축 하 였다. 농축 후 노말헥산 $5 \mathrm{~mL}$ 에 재용해 하였으며 활성실리카겔 을 사용하여 정제하였다. 이와 같은 정제 방법을 따라 정제 후 수집한 용출분획을 회전증발 농축기를 사용하여 감압 농축하였 으며 toluene으로 재용해 후 분석하였다. 회수율을 구한 결과 분 석 대상 성분은 $70-120 \%$ 이었다. 분석대상 물질의 검출한계는 0.001-0.005 ppm 수준이었다.

농약 유래 잔류유기화학물질의 정성 및 정량 분석. 분별깔때기 에 농업용수 시료 $250 \mathrm{~mL}$ 를 넣고 염석효과를 주기 위해 염화 나트륨 $15 \mathrm{~g}$ 을 충분히 녹인 다음 시료 중 dichloromethane을 각 각 $250 \mathrm{~mL}$ 를 첨가한 후 15 분간 진탕하였다. 추출을 2 회 반복 실시한 후 이들을 dichloromethane 층을 합하여 무수황산나트륨 으로 탈수한 후 회전증발 농축기를 이용하여 농축하였다. 시료 전처리 방법은 위에 기술한 바와 같이 실시하였으며, 사용한 컬 럼의 크기는 안지름 $10 \mathrm{~mm}$, 길이 $300 \mathrm{~mm}$ 의 하부에 테프론 재 질의 콕이 부착된 것을 이용하였다. 활성화된 실리카겔 $4 \mathrm{~g}$ 은 노말헥산에 넣어 컬럼에 충진하여 사용하였다. 이때 기포가 생 기지 않도록 유의하였다. 이후 노말헥산을 $200 \mathrm{~mL}$ 흘려서 얻은 용출액을 최종 액량이 $1 \mathrm{~mL}$ 가 되도록 toluene으로 재용해 하였 다. 재용해한 시료를 $\mathrm{GC}-\mathrm{ECD}$ 로 분석하였으며 검출된 물질은 GC-MSD로 확인하였다(Table 3).

농업용수 시료 중 검출된 $\mathrm{POPs}$ 는 $\alpha-, \beta$-endosulfan 그리고 endosulfan sulfate였으며 다른 종류의 농약 유래 POPs는 검출 한계 이하로 검출되었다. 특히, 2 번지역부터 7 번지역까지의 시 


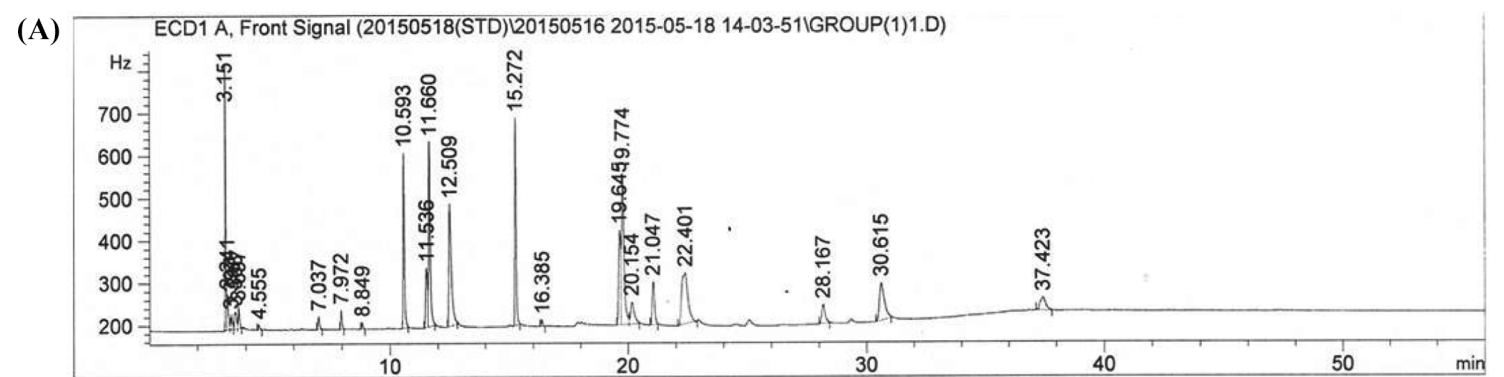

(B)

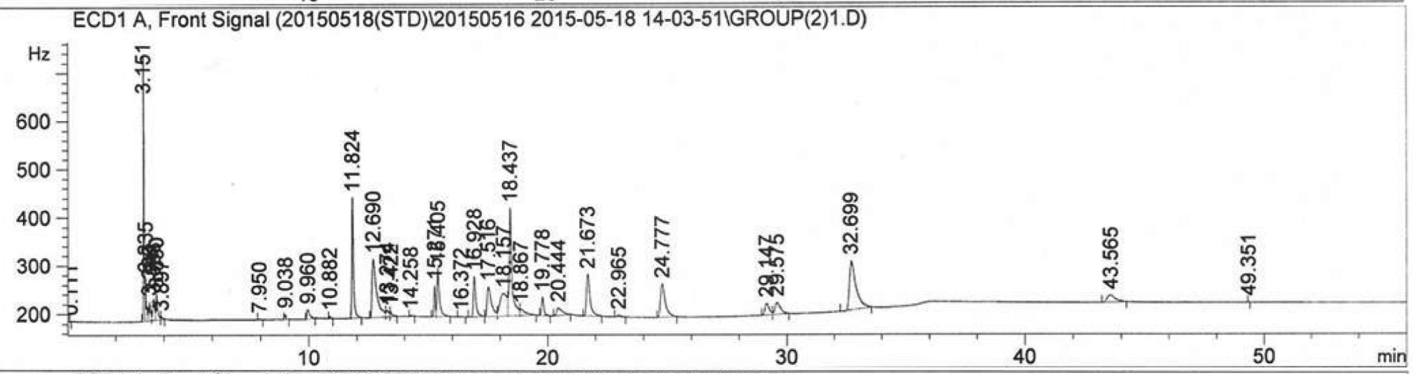

(C)

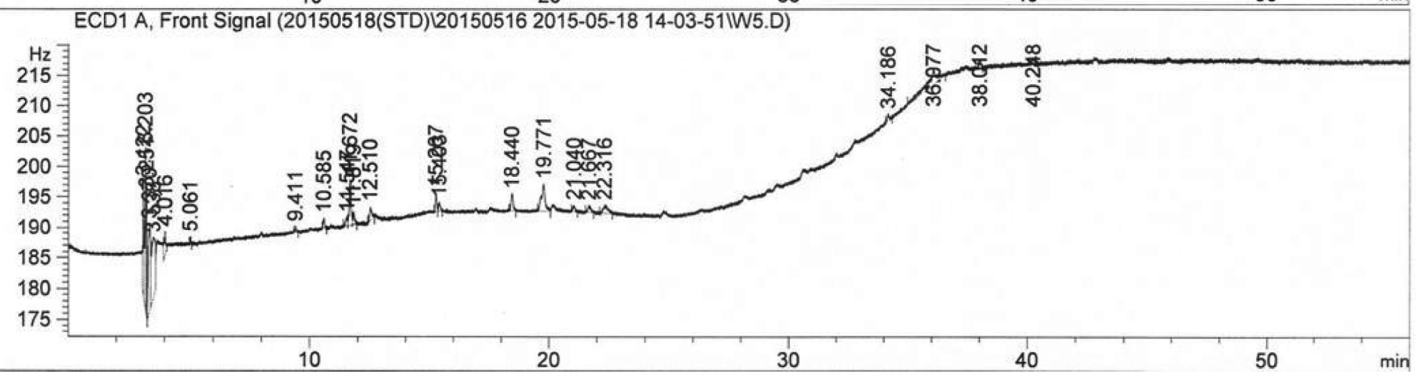

Fig. 1 GC-ECD chromatograms for monitoring pesticide-originated persistent organic pollutants in agricultural waters located in Chungchung province, Korea. (A), Type 1 standards; (B) Type 2 standards; (C) chromatogram after GC-ECD analysis of the sample No. 5 collected at the grid reference of $36^{\circ} 45^{\prime} 24^{\prime \prime} \mathrm{N} 126^{\circ} 53^{\prime} 48^{\prime \prime} \mathrm{E}$.

Table 4 Concentrations $(\mathrm{ng} / \mathrm{mL}$ ) of pesticide-originated persistent organic pollutants (POPs) and currently used organochlorine pesticides in agricultural waters in Chungcheong Province, Korea

\begin{tabular}{|c|c|c|c|c|c|c|}
\hline No. & $\alpha$-endosulfan & $\beta$-endosulfan & Endosulfan sulfate & Triadimefon & Chlorpyrifos & Tolyfluanid \\
\hline 1 & -a) & - & - & - & - & - \\
\hline 2 & 0.44 & 0.55 & 0.13 & - & - & 0.33 \\
\hline 3 & 0.41 & 0.04 & - & 2.04 & - & 0.30 \\
\hline 4 & 0.43 & 0.04 & - & 2.05 & 3.85 & 0.30 \\
\hline 5 & 0.04 & 0.04 & 1.10 & 2.03 & - & - \\
\hline 6 & 0.38 & 0.02 & - & - & 1.34 & 0.27 \\
\hline 7 & 0.37 & 0.01 & - & - & - & 0.26 \\
\hline 8 & - & - & - & - & - & 0.27 \\
\hline 9 & - & - & - & - & - & - \\
\hline 10 & - & - & 1.13 & - & - & - \\
\hline 11 & - & - & - & - & - & - \\
\hline 12 & - & - & - & - & - & - \\
\hline 13 & - & - & - & - & - & - \\
\hline 14 & - & - & - & - & 1.56 & - \\
\hline 15 & - & - & 1.12 & - & - & - \\
\hline
\end{tabular}

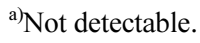

료에서 $\alpha-, \beta$-endosulfan 그리고 endosulfan sulfate 모두가 검 출되었다. 검출 농도는 Table 4에 나타낸 바와 같이 0.01 부터 $1.13 \mathrm{ng} / \mathrm{mL}$ 의 endosulfan류의 POPs 물질이 검출되었다. $\alpha-$ endosulfan은 수계생물에 상당히 유독한 POPs 물질이며, 96시
간 노출 시 $\alpha$-endosulfan의 rainbow trout에 대한 반수치사농도 $\left(\mathrm{LC}_{50}\right)$ 는 $1.75 \mathrm{ng} / \mathrm{mL}$ 이었다(Capkin 등, 2006). 따라서, 충청도 지역 농업용수 시료에서 검출된 $\alpha$-endosulfan의 농도는 상당히 높은 수치이며, 해당수계지역에서 수서생물 서식 및 생태에 큰 
영향을 줄 것으로 보여진다. $\beta$-endosulfan의 경우는 $\alpha$-endosulfan 의 경우 보다 검출 범위가 더 넓은 0.01 부터 $0.55 \mathrm{ng} / \mathrm{mL}$ 이었다. 이 외에도 endosulfan sulfate의 경우 네 지역에서 0.13 부터 1.13 $\mathrm{ng} / \mathrm{mL}$ 의 농도로 존재하였다. 종합하여 보면, endosulfan류의 물 질들의 총합은 적게는 0.38 부터 $1.18 \mathrm{ng} / \mathrm{mL}$ 수준이었다. Park (2011)에 의하면 endosulfan은 논토양 및 시설하우스 토양 시료 중 가장 빈번히 검출되는 농약으로서 검출빈도가 $38.8 \%$ 였으며 검출농도는 3-155 ng/g 수준이었다. 이러한 결과로부터 농업용 수에서 검출된 endosulfan은 농경지 토양에서 유래된 것으로 추 측된다. 또한, $\mathrm{Kim}$ 등(2014)에 의하면 endosulfan은 산업지역토 양에서 $0.198-2.357 \mathrm{ng} / \mathrm{g}$, 도심 거주지역 토양에서 $0.145-7.468$ $\mathrm{ng} / \mathrm{g}$, 그리고 농업지역 토양에서 $0.249-8.418 \mathrm{ng} / \mathrm{g}$ 수준에서 잔 류하였다. 따라서, endosulfan류 물질은 국내 전지역에서 고르게 잔류하는 양상을 띠고 있으며 이는 시민의 건강에도 심각한 영 향을 미칠 것으로 사려된다. Endosulfan에 의한 오염은 공기 중 에서도 발견되는데 미국 플로리다 주의 Everglades 지역은 17 $\mathrm{ng} \mathrm{m}^{-3}$ 수준의 endosulfan이 공기 중에서 검출되었다 (Hapeman 등, 2013). 따라서, endosulfan을 포함한 농약계 POPs의 환경 중 동태를 지속적으로 파악하는 것이 매우 중요하다(Kim과 Lee, 2010). endosulfan류 외에도 유기염소계 농약의 분석을 통하여 농업용수 시료 중 3 번 지역부터 5 번 지역까지 Triadimefon이 2.03- $2.05 \mathrm{ng} / \mathrm{mL}$ 수준에서 검출되었고, tolyfluanid는 $2,3,4$, $6,7,8$ 번 지역 시료에서 검출되었으며 농도는 $0.26-0.33 \mathrm{ng} / \mathrm{mL}$ 였다. 흥미로운 것은 chlorpyrifos가 $4,6,14$ 번 지역에서 검출 되었으며 각각의 농도는 $3.85,1.34,1.56 \mathrm{ng} / \mathrm{mL}$ 까지 다양하였다. 본 연구를 통하여 충청 지역의 농업용수 시료에서 엔도설판계 POPs가 검출되었으며 따라서 이들의 농업환경 중 동태에 대한 지속적인 관찰이 필요한 시점이라고 보여진다.

\section{초 록}

잔류성유기오염물질(POPs)은 현재 사용이 금지된 유기염소계 농 약을 포함하고 이들은 국내 농업환경 중 발견이 되며 이들의 작물로의 이동 또한 보고되고 있다. 본 연구는 충청도 지역 15 곳의 농업용수를 채취하여 이들 시료 중 $\mathrm{POPs}$ 를 모니터링 하 고자 하였으며 이들 시료는 액액분배를 통한 추출 및 정제컬럼 을 이용한 정제과정을 거쳐 기체크로마토그래피에 의하여 분석 되었다. 농약유래 POPs 중 $\alpha$-endosulfan이 $0.01-1.13 \mathrm{ng} / \mathrm{mL}$ 수 준에서 검출되었으며, $\beta$-endosulfan과 endosulfan sulfate는 각각 $0.01-0.55 \mathrm{ng} / \mathrm{mL}$ 및 $0.13-1.13 \mathrm{ng} / \mathrm{mL}$ 수준에서 검출되었다. 총 endosulfan 검출량은 $0.38-1.18 \mathrm{ng} / \mathrm{mL}$ 이었다. 현재 사용중인 농 약 중 triadimefon 은 $2.03-2.05 \mathrm{ng} / \mathrm{mL}$ 수준에서, tolyfluanid은 $0.26-0.33 \mathrm{ng} / \mathrm{mL}$ 수준에서, chlorpyrifos는 $1.34-3.85 \mathrm{ng} / \mathrm{mL}$ 수 준에서 검출되었다. 농약계 POPs 중 endosulfan류의 물질들의 잔류가 확인되었고 이들의 환경 중 지속적인 모니터링이 필요 하다.

Keywords 농약 유래 POPs · 모니터링 · endosulfan · endosulfan sulfate

감사의 글 본 연구는 농촌진흥청 공동연구사업(세부과제명: 비의도성 잔류 유기화학물질의 모니터링 및 노출량 평가, 과제번호: PJ010922032015)의 지 원에 의해 이루어진 것임.

\section{References}

Bordas B, Belai I, and Komives T (2011) Theoretical molecular descriptors relevant to the uptake of persistent organic pollutants from soil by zucchini. A QSAR study. J Agric Food Chem 59, 2863-9.

Capkin E, Altinok I, and Karahan S (2006) Water quality and fish size affect toxicity of endosulfan, an organochlorine pesticide, to rainbow trout. Chemosphere 64, 1793-800.

Choi M and Chun MY (2007) Organochlorine pesticides concentration in soil. J Korean Soc Environ Anal 10, 169-74.

Hapeman CJ, McConnell LL, Potter TL, Harman-Fetcho J, Schmidt WF, Rice CP et al. (2013) Endosulfan in the atmosphere of South Florida: Transport to Everglades and Biscayne National Parks. Atmos Environ 66, $131-40$.

Kim BH and Lee JY (2010) Policy \& management of persistent organic pollutant in Korea. Prospectives Ind Chem 13, 1-10.

Kim D, Ryu HY, Lee JH, Lee YJ, Kim HK, Jang DD et al. (2013) Organochlorine pesticides and polychlorinated biphenyls in Korean human milk: contamination levels and infant risk assessment. $J$ Environ Sci Heal Part B 48, 243-50.

Kim EJ, Park YM, Park JE, and Kim JG (2014) Distribution of new Stockholm convention POPs in soils across South Korea. Sci Total Environ 476-477, 327-35.

Kim JH and Smith A (2001) Distribution of organochlorine pesticides in soils from South Korea. Chemosphere 43, 137-40.

Park BJ (2011) Pesticide residue monitoring and environmental exposure assessment in paddy field soil and greenhouse soils. Korean J Pestic Sci $15,1-6$.

Tsai WT (2010) Current status and regulatory aspects of pesticides considered to be persistent organic pollutants (POPs) in Taiwan. Int J Environ Res Public Health 7, 3615-27. 